\title{
Catalytic Properties of Ti-HMS with High Titanium Loadings
}

\author{
S. H. Jang, M. J. Kim, J. R. Ko, and W. S. Ahn" \\ School of Chemical Science and Engineering, Inha University, Incheon 402-751, Korea. *E-mail: whasahn@inha.ac.kr \\ Received January 14, 2005
}

\begin{abstract}
Ti-HMS samples in which titanium species exist in various forms of isolated tetrahedral state, finely dispersed $\mathrm{TiO}_{2}$ cluster, and some in extra-framework anatase phase were prepared via a direct synthesis route using dodecylamine (DDS) as a structure directing agent by systematically varying the titanium loadings between 2 and $50 \mathrm{~mol} \% \mathrm{Ti} /(\mathrm{Ti}+\mathrm{Si})$ in substrate composition. Physicochemical properties of the materials were evaluated using XRD, SEM/TEM, $\mathrm{N}_{2}$ adsorption, UV-vis and XANES spectroscopies. Catalytic properties of Ti-HMS in cyclohexene and 2,6-di-tert-butyl phenol (2,6-DTBP) oxidation using aqueous $\mathrm{H}_{2} \mathrm{O}_{2}$, and vapor phase photocatalytic degradation of acetaldehyde were evaluated. $\mathrm{High} \mathrm{H}_{2} \mathrm{O}_{2}$ selectivity was obtained in cyclohexene oxidation, and cyclohexene conversion was found primarily dependent on the amount of tetrahedrally coordinated Ti sites. For bulky 2,6-DTBP oxidation and photocatalytic oxidation of acetaldehyde, on the other hand, conversions were found dependent on the total amount of $\mathrm{Ti}$ sites and maintaining an uniform mesoporous structure in the catalysts was not critical for efficient catalysis.
\end{abstract}

Key Words : Ti-HMS, Photocatalytic degradation, Cyclohexene, 2,6-di-tert-butyl phenol, Acetaldehyde

\section{Introduction}

Redox molecular sieves promising for transformations of large organic molecules in liquid phase reactions had emerged recently by incorporating various transition metal species such as $\mathrm{Ti}, \mathrm{V}, \mathrm{Zr}, \mathrm{Mn}$, or $\mathrm{Sn}$ into the mesoporous silica hosts of M41S type materials. ${ }^{1}$ Most of such studies investigated titanium as a model redox metal, and they were usually prepared by introducing a suitable titanium precursor during the hydrothermal synthesis steps in which surfactant templating mechanism of $\mathrm{S}^{+} \mathrm{I}^{-} / \mathrm{S}^{+} \mathrm{X}^{-} \mathrm{I}^{+}$, or $\mathrm{S}^{\circ} \mathrm{I}^{0}$ type operates in basic or neutral media. ${ }^{2}$

Most of redox molecular sieves containing titanium typically dealt with the properties of catalysts with $\mathrm{Ti}$ concentration below 2 mol\%. ${ }^{1,3-6}$ In particular, Tuel ${ }^{7}$ closely examined the modification of mesoporous silica by various hetero-elements incorporation to the framework and mentioned about the possibility of incorporating higher amount of redox metal into the silica matrix. However, higher than 5\% redox metal loadings were seldom investigated. In this work, Ti-HMS with substantially higher concentration range of $\mathrm{Ti}$ in the substrate mixture, up to 50 $\mathrm{mol} \% \mathrm{Ti} /(\mathrm{Ti}+\mathrm{Si})$, were attempted and characterized. It was expected by us that the neutral synthesis condition for HMS material supplemented with its disordered pore structure would be useful to accommodate high amounts of transition metal species than in M41S type materials prepared in basic media, since precipitation as hydroxide is less likely in neutral synthesis condition and flexibility of inter-atomic arrangement in the disordered pore shape for the former can make a room for high transition metal loadings. These porous materials were tested as catalysts for epoxidation of cyclohexene and 2,6-di-tert-butyl phenol (2,6-DTBP) oxidation using hydrogen peroxide as an oxidant. Photocatalytic oxidation of vapor phase acetaldehyde was also conducted to investigate the dependence of the catalytic activities on the nature of $\mathrm{Ti}$ species. In the past, it has been usually suggested that the active sites for epoxidation and similar oxidation reactions are the tetrahedrally coordinated Ti species in Ti-containing catalysts, ${ }^{3,5}$ but some conflicting evidences are being accumulated. ${ }^{8-12}$ Apparently, other parameters such as the support properties of hydrophobicity /hydrophilicity, ${ }^{6}$ acidity, the nature and accessibility of Tispecies, and the particle size may also affect the catalytic performances. This set of different reactions will serve to have an objective evaluation the dependence of the catalytic property on the nature of Ti-species. A series of titania-silica aerogels with $0-100 \% \quad \mathrm{TiO}_{2}$ contents were synthesized before and similar investigation on the nature of Ti-species has been reported. ${ }^{8,9,13,14}$

\section{Experimental Section}

A series of Ti-HMS were prepared following the synthesis protocol similar to that reported by Zhong and Pinnavaia. ${ }^{2}$ The molar gel composition of the substrate mixture was $\mathrm{SiO}_{2}: \mathrm{TiO}_{2}: 0.2 \mathrm{DDA}($ dodecylamine $): 9 \mathrm{EtOH}: 0.02 \mathrm{HCl}$ : $160 \mathrm{H}_{2} \mathrm{O}$, where $\mathrm{x}$ was varied between 0.02 and 1 . Titanium isopropoxide (TIP) and TEOS were used as titanium and silica source, respectively. TEOS and TIP in ethanol solution was added to the solution of DDA in water and $\mathrm{HCl}$ under vigorous stirring and aged at ambient condition for $24 \mathrm{~h}$ to obtain a product. All samples were filtered, dried at room temperature, and calcined at $823 \mathrm{~K}$ for $4 \mathrm{~h}$. The crystallinity of the samples prepared was measured by X-ray diffraction using Ni-filtered $\mathrm{CuK} \alpha$ radiation (Philips, PW-1700), and the morphology of the samples was examined by SEM (Hitachi, S4200) and TEM (Philips, CM 200). The specific surface area and average pore diameters were determined by $\mathrm{N}_{2}$ adsorption-desorption with the BET method at liquid 
nitrogen temperature using a Micromeretics ASAP 2000 automatic analyzer. UV-vis diffuse reflectance spectroscopy was performed on a Varian CARY3E double-beam spectrometer using $\mathrm{MgO}$ as a reference in the range of 190$750 \mathrm{~nm}$ in ambient conditions. Titanium content of the TiHMS was analyzed using SEM-EDS. XANES spectra were obtained at beamline $3 \mathrm{C} 1$ in Pohang Accelerator Laboratory (PAL) in Pohang, Korea. Measurements were carried out above the Ti $\mathrm{K}$ edge $(4966 \mathrm{eV})$ at room temperature in transmission mode.

The catalytic activities of all samples were measured for the liquid phase oxidation of 2,6-DTBP and cyclohexene epoxidation using $\mathrm{H}_{2} \mathrm{O}_{2}$ as an oxidant. Reactions were carried out under vigorous stirring in a two-neck pyrex round bottom reactor equipped with a condenser and a thermometer. The oxidation of 2,6-DTBP was conducted at $337 \mathrm{~K}$ for $2 \mathrm{~h}$ using $10 \mathrm{mmol}$ of substrate, $100 \mathrm{mg}$ of catalyst, $10 \mathrm{~g}$ acetone as a solvent, and $30 \mathrm{mmol}$ of $35 \mathrm{wt} \%$ $\mathrm{H}_{2} \mathrm{O}_{2}$. Cyclohexene epoxidation reaction was carried out at $333 \mathrm{~K}$ for $3 \mathrm{~h}$ using $33 \mathrm{mmol}$ substrate, $10 \mathrm{mmol}$ of $35 \mathrm{wt} \%$ $\mathrm{H}_{2} \mathrm{O}_{2}, 20 \mathrm{~mL}$ methanol (solvent), and $200 \mathrm{mg}$ catalyst. The products were analyzed by using a HP5890 series II GC equipped with a HP-5 capillary (for 2,6-DTBP reaction) or Supelco NukolTM fused silica capillary column (for cyclohexene reaction) and a FID. Absolute GC calibration was done using standard samples for product analysis. $\mathrm{H}_{2} \mathrm{O}_{2}$ selectivity in these oxidation reactions was measured by cerium (IV) sulfate (Fluka, $0.1 \mathrm{~mol} / \mathrm{L}$ ) titration using ferroin indicater (Aldrich, $0.1 \mathrm{wt} \%$ solution in water ${ }^{15}$ ). Photocatalytic degradation of acetaldehyde of $c a .1200 \mathrm{ppm}$ concentration was carried out using a $9 \mathrm{~W}$ UV-lamp set in a recycled reactor connected to an on-line GC via a solenoid sampling valve. For measuring the catalytic activities, TiHMS samples $(0.6 \mathrm{~g})$ were combined with a binder solution (Enpion Co., $15 \mathrm{~g}$ ) and mixed homogeneously in sonic treatment for $30 \mathrm{~min}$ and bar-coated on a piece of aluminum plate. After heating at $373 \mathrm{~K}$ in a convection oven, same coating procedure was repeated 3 times. After installing the Ti-HMS coated plate inside a reactor, acetaldehyde was

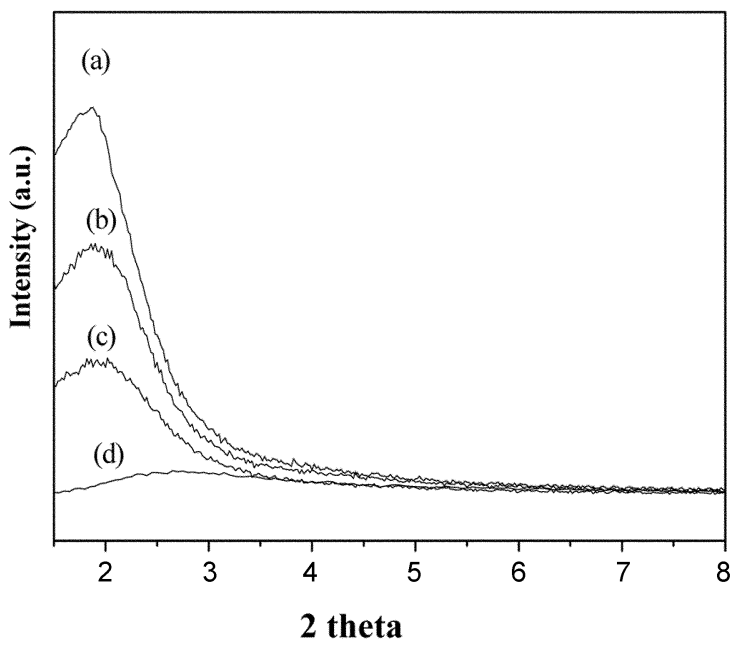

introduced and kept for 30 min before a UV- lamp was turned on to commence the photocatalytic reaction.

\section{Results and Discussion}

Low angle XRD pattern of Ti-HMS in Figure 1 showed a peak which might be indexed with the (100) plane, and shifted slightly to the right (unit cell parameter contraction) and rapidly deteriorated as the Ti content in the synthesis mixture increases from $\mathrm{Ti} /(\mathrm{Ti}+\mathrm{Si})=2$ to $50 \%$. HMS structure was maintained up to $\mathrm{Ti} /(\mathrm{Ti}+\mathrm{Si})=20 \%$, but virtually a flat XRD pattern was obtained with $\mathrm{Ti} /(\mathrm{Ti}+\mathrm{Si})=$ $50 \%$. However, as shown in Figure 2, some of the well known disordered mesopores of HMS material were still clearly visible by $\mathrm{TEM}$ even at $\mathrm{Ti} /(\mathrm{Ti}+\mathrm{Si})=50 \%$. Concurrently, particle size of spherical morphology grew from 40 to $120 \mathrm{~nm}$ as the titanium loading increased from 2 to $20 \%$. Small anatase peak was detected in high angle XRD region in Figure 1 after signal amplification, which grew with titanium content. The high angle peak (a) at $2 \% \mathrm{Ti}$ is, however, believed to be due to amorphous nature of pore walls rather than contribution from anatase phase. Table 1 summarizes the textual properties of Ti-HMS samples prepared, which demonstrate gradual decreases of surface area, pore volume, and average pore size accompanied by increases in Ti content of the synthesis mixture. Much the same trend in textual property was also reported by Davis and Liu. ${ }^{16}$ According to the SEM-EDS analysis, virtually all the $\mathrm{Ti}$ in the synthesis mixture was incorporated to the solid product except the case with $\mathrm{Ti} /(\mathrm{Ti}+\mathrm{Si})=50 \%$, which indicated that approximately $80 \%$ of Ti in the substrate was incorporated to the product in various forms. Pore volume of the Ti-HMS prepared in this study compares very favorably over the one reported by Yanishpolskii et al. ${ }^{17} ; 1.13 \mathrm{~cm}^{3} / \mathrm{g}$ compared with $0.59 \mathrm{~cm}^{3} / \mathrm{g}$ at $\mathrm{Ti} /(\mathrm{Ti}+\mathrm{Si})=50 \%$. As a comparison, optimum dispersion of $\mathrm{Ti}$ was reported to be achieved at $20 \%$ Ti loadings in $\mathrm{TiO}_{2}-\mathrm{SiO}_{2}$ aerogels. ${ }^{9}$

UV-vis spectra of the calcined Ti-HMS samples were given in Figure 3. The band centered at $c a .220 \mathrm{~nm}$ and

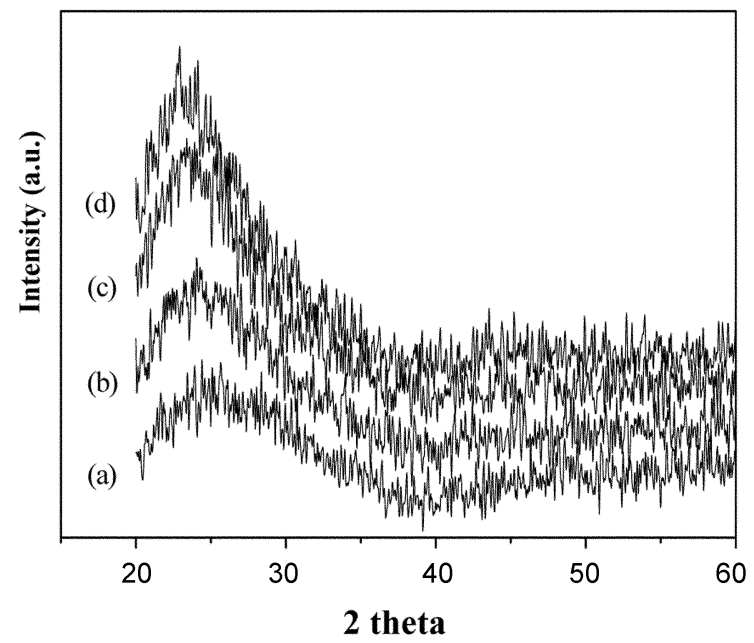

Figure 1. X-ray diffraction patterns of calcined samples; (a) 2\% Ti-HMS, (b) 5\% Ti-HMS, (c) 20\% Ti-HMS, (d) 50\% Ti-HMS. 


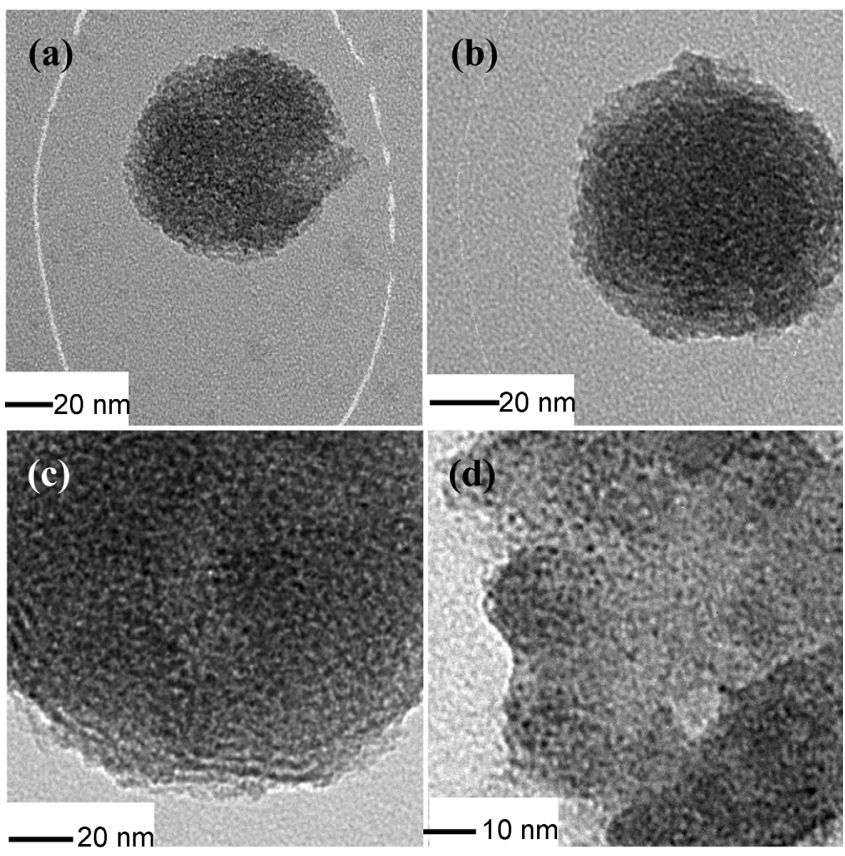

Figure 2. TEM images of (a) 2\% Ti-HMS, (b) 5\% Ti-HMS, (c) $20 \%$ Ti-HMS, (d) $50 \%$ Ti-HMS.

Table 1. Structural data of Ti-HMS materials

\begin{tabular}{ccccc}
\hline $\begin{array}{c}\text { Catalysts } \\
\mathrm{Ti} /(\mathrm{Ti}+\mathrm{Si}) \\
(\mathrm{mol} \%, \\
\text { substrate) }\end{array}$ & $\begin{array}{c}\text { BET surface } \\
\text { area } \\
\left(\mathrm{m}^{2} / \mathrm{g}\right)\end{array}$ & $\begin{array}{c}\text { BJH pore } \\
\text { volume } \\
\left(\mathrm{cm}^{3} / \mathrm{g}\right)\end{array}$ & $\begin{array}{c}\text { BJH pore } \\
\text { size } \\
(\AA)\end{array}$ & $\begin{array}{c}\text { EDS Data* } \\
\mathrm{Ti} /(\mathrm{Ti}+\mathrm{Si}) \\
(\mathrm{mol} \%, \\
\text { calcined })\end{array}$ \\
\hline Ti-HMS (2) & 709 & 1.69 & 36.2 & 2.9 \\
Ti-HMS (5) & 865 & 1.74 & 28.0 & 5.9 \\
Ti-HMS(20) & 724 & 1.13 & 25.9 & 19.2 \\
Ti-HMS(50) & 509 & 0.74 & 20.5 & 38.5 \\
\hline
\end{tabular}

*Averaged after measurement at 5 spots on the sample. (standard deviation $\pm 5 \%$ of the values measured.)

shoulder at $270 \mathrm{~nm}$ in UV-vis spectra grew concurrently in intensity as the amount of titanium in the substrate mixture increases. The spectra of Ti-containing mesoporous materials are usually characterized by broad absorption bands centered at 220 and $260-270 \mathrm{~nm}$ as reported by Zhang et al. ${ }^{2}$ For microporous TS-1, an intense band at $c a$. $220 \mathrm{~nm}$ has been assigned to the ligand-to-metal charge transfer involving isolated $\mathrm{Ti}$ atoms in tetrahedral coordination. According to these assignment, the band at $c a .220 \mathrm{~nm}$ in Ti-substituted mesoporous materials may be associated with isolated Ti(IV) framework sites fundamentally similar in character to those in TS-1. The shoulder at $270 \mathrm{~nm}$ probably corresponds to partially polymerized hexa-coordinated $\mathrm{Ti}$ species, and some Ti-O-Ti clusters are suspected to co-exist with the isolated Ti sites in all the mesoporous samples. UV signals of Ti-O-Ti nano-clusters grew in size and increasingly redshifted with increasing Ti loading, and at $\mathrm{Ti} /(\mathrm{Ti}+\mathrm{Si})=50 \%$, this shift to near $370-410 \mathrm{~nm}$ region indicated the presence of emerging anatase phase. Overall UV-vis spectral features seem to indicate that growth in polymeric Ti species is more significant than those in isolated sites with increasing $\mathrm{Ti}$

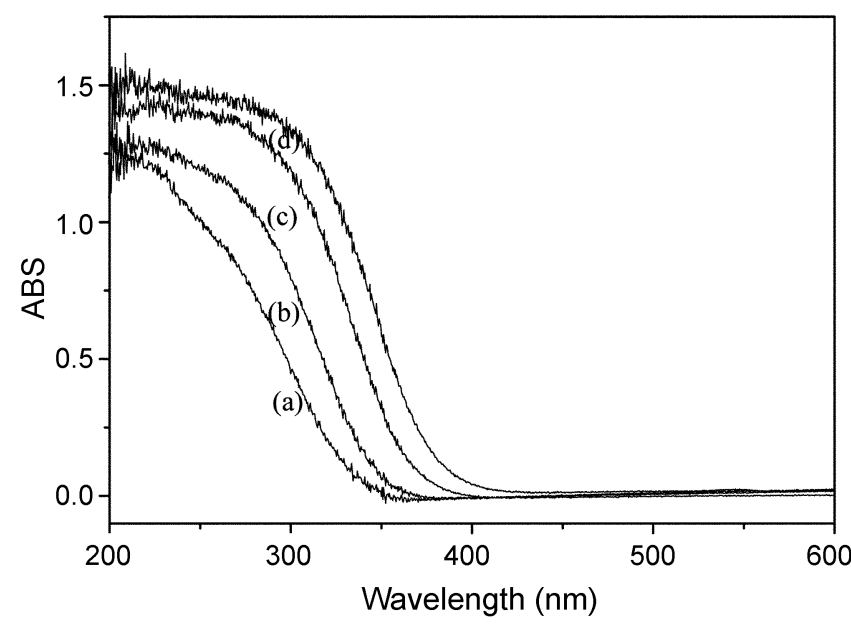

Figure 3. UV-Vis spectra of (a) 2\% Ti-HMS, (b) 5\% Ti-HMS, (c) $20 \%$ Ti-HMS, (d) $50 \%$ Ti-HMS.

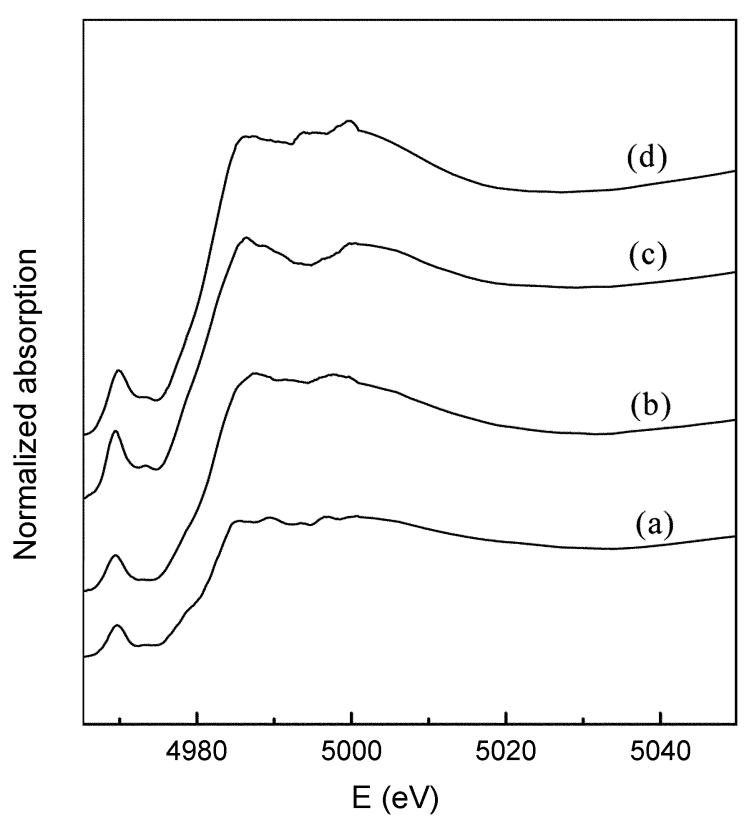

Figure 4. XANES spectra of (a) 2\% Ti-HMS, (b) 5\% Ti-HMS, (c) $20 \%$ Ti-HMS, (d) $50 \%$ Ti-HMS.

contents.

XANES spectra of the calcined Ti-HMS samples with different Ti loadings are compared in Figure 4. A single strong pre-edge peak which can be assigned to titanium species in tetrahedral or distorted octahedral symmetry due to hydration is clearly visible at $c a .4967 \mathrm{eV}$ and this feature is quite different from those of anatase or rutile which displays undulating multiple low density pre-edge peaks at the same region..$^{18}$ However, as the Ti loading increases between $\mathrm{Ti} /(\mathrm{Ti}+\mathrm{Si})=5$ to $20 \%$, this characteristic single peak begins to develop a small bump next to it, which signals steady growth of Ti-O-Ti species, which agrees well with the trends shown by UV-Vis spectroscopy and XRD analysis.

To evaluate the catalytic properties of Ti-HMS samples prepared, liquid phase oxidation of cyclohexene and more 
Table 2. Catalytic reaction results for cyclohexene epoxidation

\begin{tabular}{|c|c|c|c|c|c|c|c|c|}
\hline \multirow{2}{*}{$\begin{array}{l}\text { Catalysts } \mathrm{Ti} /(\mathrm{Ti}+\mathrm{Si}) \\
(\mathrm{mol} \%)\end{array}$} & \multirow{2}{*}{$\begin{array}{c}\text { Cyclohexene } \\
\text { Conversion (\%) }\end{array}$} & \multirow{2}{*}{$\begin{array}{c}\mathrm{H}_{2} \mathrm{O}_{2} \text { conversion } \\
(\%)\end{array}$} & \multirow{2}{*}{$\begin{array}{c}\mathrm{H}_{2} \mathrm{O}_{2} \text { selectivity } \\
(\%)^{a}\end{array}$} & \multicolumn{5}{|c|}{ Selectivity (\%) } \\
\hline & & & & epoxide & 1-ol & 1-one & ether & diol \\
\hline Ti-HMS (2) & 19.4 & 68 & 81 & 2.1 & 3.6 & 10.6 & 77.3 & 6.4 \\
\hline Ti-HMS (5) & 20.0 & 76 & 71 & 4.2 & 5.3 & 12.8 & 68.8 & 8.9 \\
\hline Ti-HMS (20) & 20.2 & 77 & 71 & 3.5 & 5.1 & 12.7 & 68.7 & 10.0 \\
\hline Ti-HMS (50) & 21.9 & 78 & 75 & 1.5 & 5.3 & 13.5 & 72.2 & 7.5 \\
\hline
\end{tabular}

Reaction conditions : $0.2 \mathrm{~g}$ catalyst, $20 \mathrm{~mL}$ methanol, $33 \mathrm{mmol}$ cyclohexene, $10 \mathrm{mmol} \mathrm{H}_{2} \mathrm{O}_{2}, 60{ }^{\circ} \mathrm{C}$ for $3 \mathrm{~h}$. ${ }^{a}$ Epoxidation selectivity for path A below.

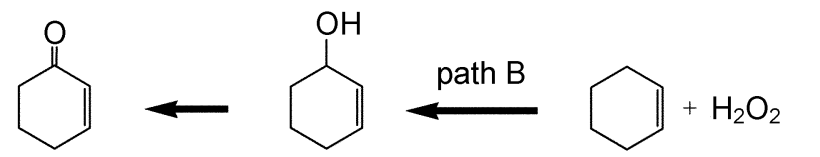

bulky 2,6-DTBP oxidation was carries out, and the corresponding conversion and selectivity data are summarized in Table 2 and 3, respectively. For cyclohexene epoxidation, the major products were cyclohexene diol and its methyl ethers as reported by others. ${ }^{3-6,19}$ Lewis acid sites of titanium containing mesoporous materials are believed to convert the initially formed epoxide to diols and mono- and di-alkyl ethers via further reaction with water and methanol. ${ }^{20}$ Cyclohexene conversion remained almost constant with TiHMS above $2 \%$ Ti loading. $\mathrm{H}_{2} \mathrm{O}_{2}$ selectivity, on the other hand, decreased with increases in titanium content, but no significant detrimental reduction of $\mathrm{H}_{2} \mathrm{O}_{2}$ selectivity due to decomposition was resulted by the surplus titanium species in other samples with the higher $\mathrm{Ti} /(\mathrm{Ti}+\mathrm{Si})$ values. Reddy et $a l .^{21}$ also reported earlier that Ti-HMS exhibited better $\mathrm{H}_{2} \mathrm{O}_{2}$ selectivity compared to Ti-MCM-41, and decomposition of $\mathrm{H}_{2} \mathrm{O}_{2}$ was very limited, whereas virtually all the remaining $\mathrm{H}_{2} \mathrm{O}_{2}$ was decomposed in the presence of Ti-MCM-41. The outcome of 2,6-DTBP oxidation, on the other hand, shows that conversion increases smoothly with Ti contents of the Ti-HMS samples. It seems that those Ti-O-Ti nano-sized clusters identified earlier in the UV-vis spectra are also involved in this type of reaction, even though these sites are apparently less active than those $\mathrm{Ti}$ sites in tetrahedral coordination. Again, $\mathrm{H}_{2} \mathrm{O}_{2}$ selectivity declined somewhat

Table 3. Catalytic reaction results for 2,6-DTBP oxidation

\begin{tabular}{cccc}
\hline $\begin{array}{c}\text { Catalyst } \\
\mathrm{Ti} /(\mathrm{Ti}+\mathrm{Si}) \\
(\mathrm{mol} \%)\end{array}$ & $\begin{array}{c}\text { 20nversion } \\
(\mathrm{mol} \%)\end{array}$ & $\begin{array}{c}\mathrm{H}_{2} \mathrm{O}_{2} \text { Efficiency } \\
(\mathrm{mol} \%)\end{array}$ & $\begin{array}{c}\text { Quinone Selectivity } \\
(\text { mol\%) }\end{array}$ \\
\hline Ti-HMS (2) & 18.1 & 40.6 & $>97$ \\
Ti-HMS (5) & 22.1 & 31.1 & $>97$ \\
Ti-HMS (10) & 23.6 & 33.5 & $>97$ \\
Ti-HMS (50) & 32.7 & - & $>97$ \\
\hline
\end{tabular}

Reaction conditions : $0.1 \mathrm{~g}$ catalyst, $10 \mathrm{~g}$ acetone, $10 \mathrm{mmol}$ 2,6-DTBP, $30 \mathrm{mmol} \mathrm{H}_{2} \mathrm{O}_{2}, 60^{\circ} \mathrm{C}$ for $2 \mathrm{~h}$.

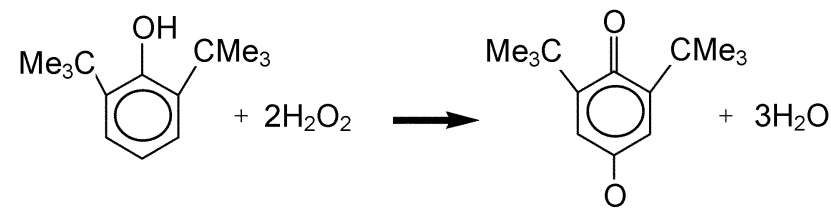

path A<smiles>C1CCC2OC2C1</smiles><smiles>CC=CCCCCCO</smiles><smiles>[R]OC1CCCCC1O</smiles>

with conversion at higher titanium loadings. This is very much in line with the recent finding that $\mathrm{TiO}_{2}$ nanoparticles, which are obtained by reaction between a hexanuclear titanium oxo cluster and a calcined SBA- 15 , are active and selective in epoxidation of aromatic molecules. ${ }^{12}$ It was also noteworthy that structural order of the HMS, which deteriorated with $\mathrm{Ti}$ in the synthesis mixture, did not result in any adverse effect in 2,6-DTBP conversions. When one considers the report that 2,6-DTBP oxidation proceeded with negligible conversion with amorphous $\mathrm{SiO}_{2}-\mathrm{TiO}_{2},{ }^{21}$ a further investigation will be useful to compare the surface properties of $\mathrm{Ti}$ containing materials prepared by sol-gel with the one prepared by the supramolecular assembly route such as Ti-HMS in the future.

Photocatalytic degradation of acetaldehyde in vapor phase was also conducted using selected Ti-HMS samples and the conversion profiles are shown in Figure 5. Performances were also compared with a commercial photocatalytic material, Degussa P-25 powder. As was the case in 2,6DTBP oxidation, removal of acetaldehyde increased with titanium loadings and Ti-HMS with $\mathrm{Ti} /(\mathrm{Ti}+\mathrm{Si})=50 \%$, in particular, showed even better performance than Degussa P-

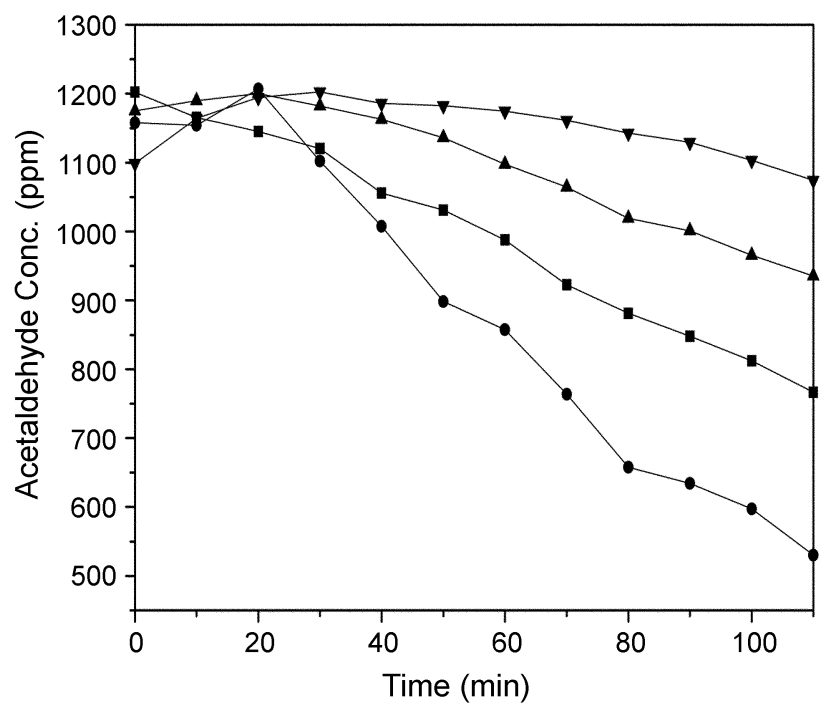

Figure 5. Photocatalytic degradation of acetaldehyde; $\square$ Degussa $\mathrm{P}-25$, 50\% Ti-HMS, $\triangle 20 \%$ Ti-HMS, $\nabla 5 \%$ Ti-HMS. 
25. Provided that a Ti-containing material has high contents of $\mathrm{Ti}$ in well-dispersed states, high structural order of a mesoporous material is not important in this case. Thus, high potential of a mesoporous material as a photo-catalyst was demonstrated, and it is the mesoporous materials with substantially high titanium contents, which are more practical for handling environmental problems despite less active turnover rates reported for Ti-O-Ti polymeric species than isolated Ti sites. ${ }^{22}$

\section{Conclusions}

Ti-HMS with Ti loadings up to $20 \mathrm{~mol} \%$ could be prepared. As the titanium content increases in HMS, structural deterioration took place accompanied by increases in Ti-OTi nano-cluster populations. Significant surface area and mesopore arrangement were, however, still found retained after introduction of such high Ti loadings. Conversion of cyclohexene in epoxidation was believed to be dependent on the concentration of isolated Ti sites, but those in the bulky 2,6-DTBP oxidation and in photocatalytic oxidation of acetaldehyde were rather dependent on the total amount of Ti sites, and keeping a uniform mesopore structure was not important for catalysis. Isolated tetrahedrally coordinated $\mathrm{Ti}$ species were not necessarily the only active species in some of oxidation reactions, and caution should be exercised to select a probe reaction to determine the coordination state of Ti species in mesoporous materials.

Acknowledgement. This work was supported by Inha University Research Fund in 2005.

\section{References}

1. Arends, I. W. C. E.; Sheldon, R. A.; Wallau, M.; Schuchardt, U.
Angew. Chem. Int. Ed. 1997, 36, 1144.

2. Zhang, W.; Froba, M.; Wang, J.; Tanev, P. T.; Wong, J.; Pinnavaia, T. J. J. Am. Chem. Soc. 1996, 118, 9164.

3. Kim, K. Y.; Ahn, W. S.; Park, D. W.; Oh, J. H.; Lee, C. M.; Tai, W. P. Bull Korean Chem. Soc. 2004, 25, 634.

4. Huang, L.; Lee, C. W.; Park, Y. K.; Park, S. E. Bull Korean Chem. Soc. 1999, 20, 747.

5. Bu, J.; Yun, S. H.; Rhee, H. K. Korean J. Chem. Eng. 2000, 17, 76.

6. Tatsumi, T.; Koyano, K. A.; Igarash, N. Chem. Commun. 1998, 325.

7. Tuel, A. Micropor. Mesopor. Mater. 1999, 27, 151.

8. Liu, Z.; Clumbaugh, G. M.; Davis, R. G. J. Catal. 1996, 159, 83.

9. Dutoit, D. C. M.; Schneider, M.; Baiker, A. J. Catal. 1995, 153, 165.

10. Hutter, R.; Mallat, T.; Baiker, A. J. Catal. 1995, 153, 177.

11. Iwamoto, M.; Tanaka, Y.; Hirosumi, J.; Nika, N.; Triwahyono, S. Micropor. Mesopor. Mater. 2001, 48, 110.

12. Tuel, A.; Hubert-Pfalzgraf, L. G. J. Catal. 2003, 217, 343.

13. Beck, C.; Mallat, T.; Burgi, T.; Baiker, A. J. Catal. 2001, 204, 428.

14. Zhao, Y.; Xu, L.; Wang, Y.; Gao, C.; Liu, D. Catal. Today 2004, $583,93$.

15. Jeffery, G. H.; Bassett, J.; Mendham, J.; Denney, R. C. Quantitative Chemical Analysis, $5^{\text {th }}$ ed.; Longman Scientific \& Technical: UK, 1989; p 384.

16. Davis, R. J.; Liu, Z. Chem. Mater. 1997, 9, 2311.

17. Yanishpolskii, V. V.; Pavlenko, A. N.; Tertykh, V. A.; Il'in, V. G.; Leboda, R.; Skubiszewska-Zieba, J. J. Therm. Anal. Calorim. 2000, 62, 569 .

18. Kim, W. B.; Choi, S. H.; Lee, J. S. J. Phys. Chem. B 2000, 104, 8670.

19. Chen, L. Y.; Chuah, G. K.; Jaenicke, S. Catal. Lett. 1998, 50, 107.

20. Kochkar, H.; Figueras, F. J. Catal. 1997, 171, 420.

21. Reddy, J. S.; Dicko, A.; Sayari, A. Synthesis of Microporous Material: Zeolites, Clays and Nanostructures; Occelli, M. L.; Kessler, H., Eds.; Marcel Dekker: New York, U. S. A. 1996; p 405.

22. Anpo, M.; Yamashita, H.; Ikeue, K.; Fujii, Y.; Zhang, S. G.; Ichihashi, Y.; Park, D. R.; Suzuki, Y.; Koyano, K.; Tatsumi, T. Catal. Today 1998, 44, 327. 